\title{
The Reform and Exploration in the Experiment Teaching Method and Instrument to Service for Local Productions and Quality Control
}

\author{
Zhengde Tan, Xinrong Song, Jiyong Deng \\ College of Chemistry and Chemical Engineering, Hunan Institute of Engineering, Xiangtan, China \\ Email: tzd0517@126.com
}

Received 28 April 2014; revised 1 June 2014; accepted 15 June 2014

Copyright (C) 2014 by authors and Scientific Research Publishing Inc. This work is licensed under the Creative Commons Attribution International License (CC BY). http://creativecommons.org/licenses/by/4.0/ cc) (i)

\begin{abstract}
A benign circulatory system on classroom-experiment-enterprise research cooperation has been constructed by a deepen experiment teaching content system. Teaching method and instrument have been reformed, and the management system and experiment teaching model have already been established. Based on the provincial chemistry experimental teaching center, a new model of personnel training has been set up both for excellent and talented students, and the idea of infiltrating the scientific research into the experimental teaching has come into being step by step
\end{abstract}

\section{Keywords}

\section{Experimental Teaching, Benign Circulatory System, Reforming, Personnel Training}

\section{Introduction}

The experiment is a way to find rules of the natural and environment under the human intervention. Theory is produced from the experiment which is also the source of the modern science and technology. Therefore, some scholars have pointed out: the experiment is the mother of science and technology. With the continuous development of higher education, improving the quality and accomplishment of the people is an important part of the universities. The universities are actively exploring a new kind of personnel training mode by which the students can develop integrally including the quality in humanity, in science, and in the practice ability. Improving the students' practical abilities can't be separated from the construction of the university laboratory. Recently, the country has proposed the excellent engineer training program. One of the key contents of improving the quality of personnel training in the local universities is embodyed in the laboratory construction, laboratory manage- 
ment and efficient use of laboratory resources. The local universities, especially the new local universities, have many problems in the lab construction, such as biased perceptions, inadequate funding, poor benefits, etc. This paper presented a new kind of laboratory construction mode which includes resource integration, school-enterprise coalition and research-education combination through the practical construction of the Practical Education Center.

Depending on the provincial model of Experimental Chemistry Teaching Centre of the innovation management system and mechanism, we aim to deepen the content of experimental teaching system, then reform experiment teaching method and instrument, further establish a virtuous cycle system of scientific research cooperation among classroom-experiment-production [1]-[4]. Along with social progress and the continuous development of science, teaching reform of our country is facing the huge challenge of the comprehensive promotion of quality education and cultivates a large number of innovative talented persons in life sciences which becomes one of the important tasks to be solved [5] [6]. Chemistry is the study of the phenomenon of life science, and it is essential for chemistry experiment. Higher education in the new period is the primary task of cultivating highlevel innovative talents, and the cultivation of innovative talents in universities is the key to students' innovation spirit and practice ability cultivation. High-school laboratory trains social need of all kinds of advanced specialized personnel, and how to improve the students' practice ability and innovation ability becomes the important thing [7] [8]. The teaching of base chemistry course construction is the basic construction of teaching core, and basechemistry experimental teaching reform is the effective training of senior innovative talents which is heavy; the basechemistry experiment curriculum reform is to improve the teaching quality of biochemistry, the only way that must be passed [9] [10]. Establishing a new platform, more and more students will inspire, and outstanding students can also be identified and further nurtured, and gradually penetrate this concept into the experiment research and teaching ideas.

\section{Upgrading Quality of Experiment Teachers}

\subsection{Establish a Teaching Competitive Mechanism}

To build the provincial chemistry experimental teaching center and play its positive effects on society. It is not enough to rely on advanced instrument and equipment, but also important to average up level and quality technical team, which directly influence the teaching quality [11]. The first problem to this case is how to improve teachers' professional skills and teaching ability as well as good moral quality. At present, some universities usually hire some so-called foreign talent as experiment teacher, which leads to low professional qualities and the age boom. Teaching competitive mechanism is supposed to build base on teaching performance, professional examination, working attitude, instrument maintenance, the feedback of students, contesting between class, mutual constraint and self-control, safety and health, and so on. Teachers of low professional skills were shifted to another position, while teachers with high educational background or given experience from enterprise undertake teaching task. The total retainer system and competitive employment were utilized. Teacher who meets all required qualifications will priority to take the job.

\subsection{Improvement of Training System}

With the rapid updating of scientific knowledge, people should constantly update their knowledge structure to keep abreast with the times [12]. We attach great importance to experiment-technology team training, adopt selfstudy and mutual learning training mode, formulated the practical training plan. For example, the teachers who are under the age of 40 must attend graduate course learning, skills training in laboratory in factories at least for two years, computer and multimedia technology study. Each experiment teaching must adopt the combination between traditional blackboard writing with media instruction. Every experiment teaching staff should go out to study and visit in two years if it is feasible. Hospital peer learning exchanges at least three or more times per year. Through training, lab teachers' knowledge will updated, the level of handing the modern technique will improved, vision will widen, and the team is broadened in the enthusiasm and working level of the experiment technical work.

\subsection{Experiment Teaching}

The file form the ministry of education of higher school about construction of experiment teaching demonstration center clearly puts forward the experiment teaching idea with "student-centered", imparting knowledge, cul- 
tivating abilities, improving quality rather than the coordination development of theoretical teaching and experimental teaching (coordination development), which changes the traditional learning notions, such as "Focuses on theory teaching, despise the experiment teaching" and "Heavy knowledge, light ability training" [13]. The experiment teaching is not an appendage of theoretical teaching, but it is a systematic subject that complements each other with theoretical teaching.

\section{Building New Experiment Teaching System}

\section{The Reform of the Experiment Teaching Contents}

In order to upgrade undergraduate teaching rapidly from integration, our experimental teaching center divides the work to several main aspects: breaking the original four basic independent experiment portions, forming the basic operation platform, specialized basic skill training, shaping comprehensive experiments layer and scientific research layer. The experiment teaching content reduces to $10 \%$ - 20\% from (by) $75 \%$ (proportion), while there will be more chance for the independent thinking and the practicing.

We increased gender experiment proportion. New open bisexual experiments were discussed by court teaching committee, and practices by the teacher personally, which make the mature research projects contented in the experimental teaching. In recent years, the institute of technology innovation for student project approval reach up to 40 items, while student complete horizontal topic which applied in this platform reach up to 12 items. Academic published papers is nearly 40, and there include five articles which are indexed by SCI, the rest are published in the core, provincial publications etc.

We still make great effort to edict and redact academic writing. We together with eight other universities jointly edited five experiment teaching materials which are consisted in the publication of the "11th five-year plan”, such as “Inorganic chemistry experiment”, “Mini organic chemistry experiment”, "analytical chemistry experiment”, “modern analytical technology” and “comprehensive chemical experiment”, which are distinct to be a mixture of Chinese and English in equal portions.

\section{The Diversification of Experimental Teaching Method}

\subsection{Perfect Opening Laboratory Using the Information Management Platform}

Experimental center applies an open experiment teaching network booking system, and each lab is equipped with multiple network terminal settings. Every appointment, laboratory consumable, equipment running status is real-time embodied in the opening experiment teaching platform. Meanwhile, director of experiment center arrange experiment teaching items reasonably, such as tutors, site, etc, while students can booking the appropriate experiment accordingly. The experiment teaching center makes full use of college information management experiment teaching platform to manage comprehensively the open experiment teaching, which meets the needs of the network experimental teaching and intelligent management.

\subsection{Establishing Perfect Network Experiment Teaching Resources Platform}

The experimental teaching center builds and improves a perfect teaching resources platform for information, where students can view the experiment teaching material such as teaching outlines, notes, teaching video, books and the knowledge frontier, or download necessary teaching software [10]-[14]. Let's take Chemoffice for Example. It provides the template of molecular formula and equipment, or some other data for chemical compounds such as $\mathrm{H}^{1} \mathrm{NMR}$ or $\mathrm{C}^{13} \mathrm{NMR}$. Students can also preview experiment (lab) report or complete related content available network, which greatly improved students' computer skills. The main teaching modules include students' experiment manuals, laboratory safety system, laboratory equipment and compensation system, the recycling system that content custody, receive, use and recycle for the reagent, the open laboratory teaching system, and every instrument operation procedures, etc.

\subsection{Factory Enterprises, Strengthen the Practice, Environmental Cooperation Go First}

We pay attention to the cultivation of practical ability. In order to strengthen practical skill, our experiment center sets up two teaching base-_inside and outside school. For the 36 weeks of practice teaching plan, each teaching arrangement should be discussed by scholastic teaching committee before carrying out. Campus practice 
system mainly completes the basic knowledge and skills training, professional basic layer, comprehensive synthetical layer, especially the training for thinking consciousness, finishing the horizontal item, extracurricular innovative experiment simultaneously, etc. External practical teaching is mainly to make students gain the ability that is extremely required. It could be knowledge applied in practical production, or solving business problems as well as realize the self-value (reflect their own values). We established the 25 practice base along with two university-enterprise construct the laboratory during years of endeavor. Environmental teaching is also on our lines. We practice green chemistry and low carbon atom economy teaching conceptions in multiple courses such as organic chemistry experiment, fine chemical products synthesis, coating process, polymer chemistry and so on.

\subsection{Perfected the Experimental Teaching Evaluation System}

In order to improve the quality of experiment teaching, experiment teaching management, quality supervision, teaching evaluation monitoring and security system, teacher will be employed through competition for jobs. Censorship was selected according to the experiment teaching experience and qualifications. In advance of setting an experimental course, teacher must be recruited and tested of lab equipment application and maintenance, multimedia courseware technology, lesson plans. The comprehensive evaluation is outstanding person writing may mount guard. Performance appraisal system: the daily task arrangement, safety, health and environment of lab for teachers and students (Both teachers and students laboratory daily management, safety, health and environmental) were evaluated, which will be one of the bases for further education of teacher. The teaching effect feedback system: Every month has two levels of class situation, colleges, students timely feedback to access the Internet, peer teacher lectures each other with established. Scientific appraisal system: Laboratory is a hotbed of experimental teaching and scientific research, personnel assessment is an important indicator of the teacher. Each teacher is required to publish an article in the provincial journal or above. The update rate (renewal rate) of the course content, which is one of the index evaluate system, are required $\geq 10 \%$.

\section{The Construction and Management of Laboratory}

\subsection{The Construction of Laboratory}

Laboratory is the window of experimental teaching, scientific research and foreign service。In order to improve the experimental environment and experimental conditions, college have invested more than 800 million to transform 20 integral laboratories, and add about 50 advanced experiment equipments together with routine experiment equipments during three years. Nearly 20 sets of experimental teaching equipment are put to use for daily teaching by teacher and student, which greatly improve the experiment teaching conditions and environment. Homemade equipment is used to train the students' comprehensive quality and innovative consciousness.

\subsection{The Management of Laboratory}

\section{Daily Teaching Management}

The lab environment and safety construction is scientific, standardized, neat, concise and efficient. Lab regulations are at rational. Each room is equipped with the necessary fire control facilities and personal protective equipment. Chemical waste is classified, and local environmental monitoring departments joint the process. The experiment teaching center is equipped with full-time personnel for instrument maintenance, who can ensure the normal operation. The instrument integrity rate is $100 \%$.

General experiment teaching instrument is equipped with a special instrument box, which efficaciously reduce the damage rate. They are checked each lab per semester, which ensure the order of experimental teaching.

\subsection{The Management of Large-Scale Instrument and Equipment}

Along with the increase of the number of large-scale instruments, management is very important as a matter of course, which calls for time and room to improve efficiency. Our aim is to obey the teaching, scientific research, overseeing and sharing, resources sharing [14]-[16]. The experimental teaching center formulates the practical solutions: implementing round-the-clock open system, posting training system, responsibility system and the network system, establishing a special instrument booking network platform, which are helpful both for students, teachers, administrators, and greatly improving the instrument utilization rate, scientific research service efficiency. 


\section{Social Benefits}

The effect is remarkable through the above reform. In the past two years, our students participated in national and provincial science and technology innovation and experimental skills contest, and have made a historic breakthrough. The second natural prize and two first provincial prizes (one national second prize, one provincial first-class prize, two provincial first-class prizes) were awarded. We have declared some provincial fine courses successfully (provincial fine-selected courses) meanwhile, such as "inorganic chemical and experimental" "trace organic chemistry experiment”. In addition, the provincial experimental teaching team and the demonstration experiment teaching center have also been successfully declared. We had trained about 10 postgraduates, one doctor for colleges and universities.

\section{Fund}

Services at the local production and quality control of the experimental teaching method and means of reform and exploration Xiang Norimichi (2010) 243 Chemistry Practice Demonstration Center Xiang Norimichi (2008). 253.

Study on the teaching method in Analytical chemistry Experiment by Market orientation, No.XJK013CJG008. [2013] 001

\section{References}

[1] Zeng, Z.-X. (2010) Initial Analysis on Visiting of Five National Experimental Chemistry Demonstration Centres. Research and Exploration in Laboratory, 29, 92-94.

[2] Han, C.-Y. (2010) Cultivating Comprehensive Media Talents through Multi-Hierarchy, Real-Type and Socialization. Research and Exploration in Laboratory, 29, 141-144.

[3] Zeng, X.-B. (2010) Deeping Experiment and Practice Teaching Reform and Improving the Cultivation Quality of Application-Oriented Talents. Research and Exploration in Laboratory, 29, 1-3.

[4] Li, Y.J. (2002) Strengthen the Title Work Promoting Laboratory Technology Assessment Team Construction. Experiment Technology and Management, 19, 133-135.

[5] Gu, C. (2010) Medical Biochemistry Experimental Teaching Reform and Exploration. Northwest Medical Education, 18, 337-339.

[6] Cheng, H. (2009) Under the New Situation on the Teaching Reform of Biochemistry Experiment. Clinical Education and General Practice, 7, 370-371.

[7] Cao, J., Li, X. and Yu, H. (2010) The Comprehensive Experiment Teaching of Medical Biochemistrypractice and Experience. Journal of Mathematical Medicine, 23, 501-503.

[8] Liu, Y.J., Liu, A. and Hou, G. (2009) Teaching Reform of Biochemical Experiment Comprehensive Experiments and Basic Experiments. China Medical Herald, 6, 128-129.

[9] Han, H. and Liu, J. (2010) Biochemistry Experimental Teaching Reform Practice and Exploration. Experimental Science Technology, 8, 128-130.

[10] Zhang, X.-B., Xu, F.-Y. and Huang, M.-X. (2009) Construction and Practice of the National Experimental Teaching Demonstration Center of Communication. Research and Exploration in Laboratory, 28, 88-90.

[11] Wang, Q. and Wang, C.H. (2010) To Strengthen the Construction of Experimental Teaching Demonstration Center of Training High Quality Creative Talents. Research and Exploration in Laboratory, 28, 87-89.

[12] Xia, Y.-W. (2006) Constructing a National Team of Teaching Laboratories. Research and Exploration in Laboratory, 25, 335-338.

[13] Zhuo, S.C. and Chen, L.P. (2006) The Connotation of Chemistry Experiment Teaching Center Construction and Teaching Practice. Experiment Technology and Management, 23, 5-9.

[14] Tan, Z.-D. and Wen, Z. (2006) Exploration and Practice of Comprehensive and Creative Experimental Teaching of Chemistry. Research and Exploration in Laboratory, 25, 96-98.

[15] Tan, Z.-D. and Song, X.-R. (2005) On the Reform of the Contents and System of the Basic Chemical Experiments. Research and Exploration in Laboratory, 24, 83-85.

[16] Wang, X.-G., Zhu, Z.-L. and Cao, T.-C. (2010) Exploration and Practice on the Full Opening of Chemical Laboratory. Research and Exploration in Laboratory, 29, 89-91. 
Scientific Research Publishing (SCIRP) is one of the largest Open Access journal publishers. It is currently publishing more than 200 open access, online, peer-reviewed journals covering a wide range of academic disciplines. SCIRP serves the worldwide academic communities and contributes to the progress and application of science with its publication.

Other selected journals from SCIRP are listed as below. Submit your manuscript to us via either submit@scirp.org or Online Submission Portal.
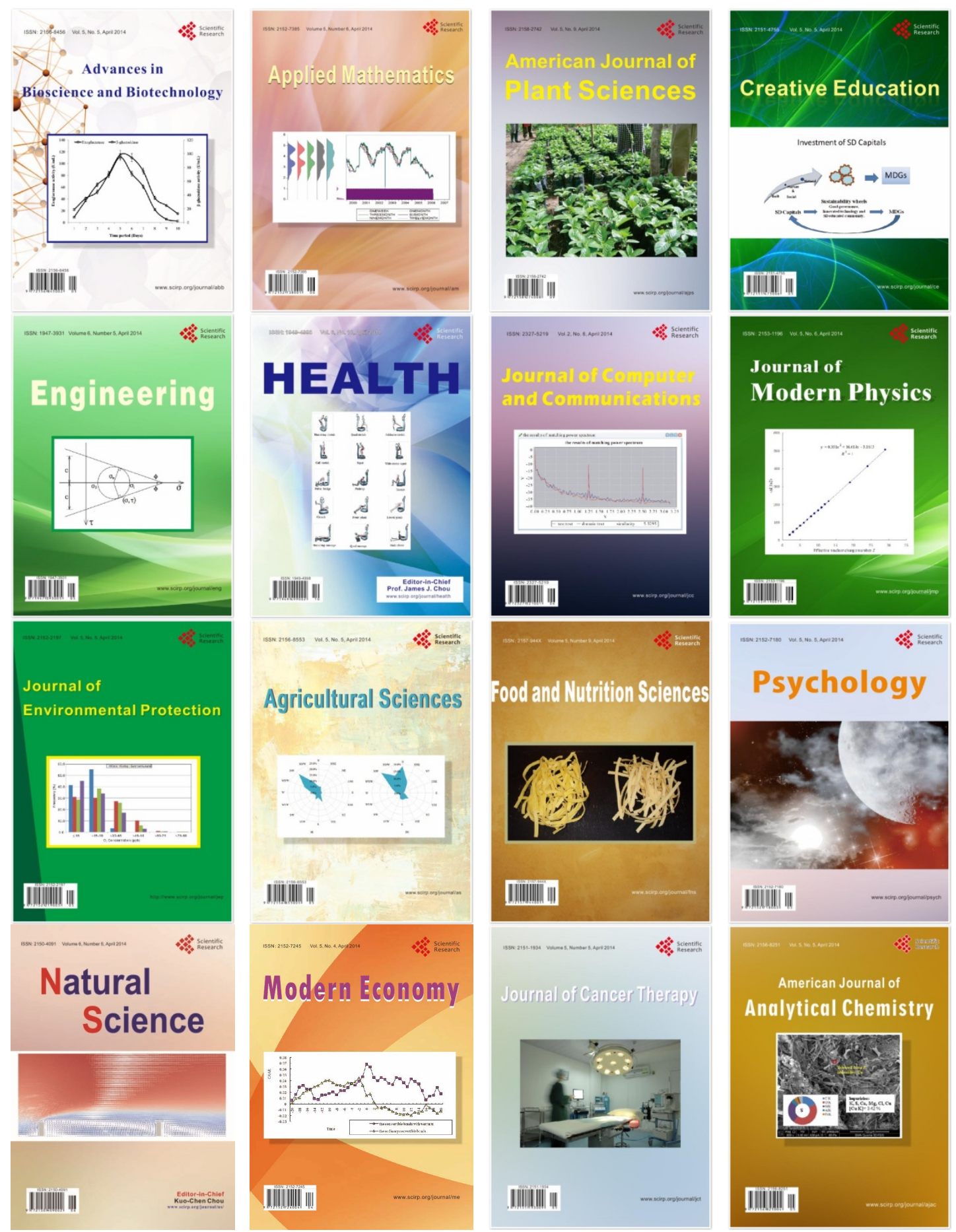